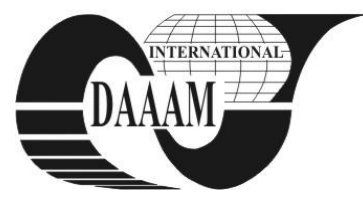

Annals of DAAAM for 2011 \& Proceedings of the 22nd International DAAAM Symposium, Volume 22, No. 1, ISSN 1726-9679 ISBN 978-3-901509-83-4, Editor B. Katalinic, Published by DAAAM International, Vienna, Austria, EU, 2011 Make Harmony between Technology and Nature, and Your Mind will Fly Free as a Bird Annals \& Proceedings of DAAAM International 2011

\title{
AUTOMATIC GENERATOR OF LIFT DISPATCHER SYSTEM MODEL
}

\author{
HOREJSI, P[etr]; HOREJSI, J[ana]; LATIF, M[uhammad] \& ULRYCH, Z[denek]
}

\begin{abstract}
This paper focuses on using discrete event simulation as a means to model and explore elevator dispatching strategies. Rockwell Arena simulation software is used as a test-bed for model building, simulation and experimentation. More strategies for the elevator dispatching system are developed and explored. The mains steps in the methodology are described with reference to a single elevator servicing a four-storey office building. The results from the case study were used for the generalization of the task using ARENA and Visual Basic for Applications. The developed environment acts as a plug-in for ARENA software and provides a common "sandbox" for user-defined elevator(s) dispatcher model construction. The solution also provides an elevator dispatcher system generator (count of floors and elevators are parameters).
\end{abstract}

Key words: simulation, discrete simulation, elevator, elevator dispatcher system, lift

\section{INTRODUCTION}

Existing buildings in many cases have been affected by urban generation programmes often with a change of use from warehousing to commercial/residential. All these buildings, new or old, require an efficient floor transportation system which traditionally is an elevator. Yet waiting for an elevator can be one of the main annoyances in one's experience with tall buildings. How long we wait depends on the dispatching strategy the elevators use to decide where to go. Not surprisingly, the times of greatest traffic and the greatest challenge to the dispatching algorithm are the morning and evening rush hours. The late eighties and nineties can be considered as the start point for exploration, especially in USA and Japan. The focus of research during the last two decades has been on controls, mechanisms, safety, etc. whilst using simple dispatching algorithms. However in more recent times some researchers have been focusing on utilising artificial intelligence in the operation of elevators. Although discrete event simulation has been used in elevator design, research has not directly addressed the effectiveness of dispatching algorithms within in-service elevators. Secondly, a literature review has highlighted that whilst simulation has been incorporated into elevator design, the models constructed all suffer from one main disadvantage: they are not parametrically built. This work attempts to address these two issues.

\section{REFERENCE CASE STUDY}

A four-storey office building was selected for this case study comprising four floors serviced by a single elevator. The simulation tool selected for this work was Rockwell Automation's Arena package, which is part of the new generation of visually interactive simulator software. Elevator traffic data was obtained through rigorous observations for a full working day. Inter-floor movement is not considered for this particular case study. The elevator traffic data was converted into a series of schedules with hourly-based durations to represent each travel direction.

\section{THE BASELINE ELEVATOR CALL STRATEGY (SCENARIO 1)}

There were a variety of logical issues that needed to be considered to enable the elevator movement. Some of the important ones were: how the elevator will a)respond to floor calls, b)take people within its capacity, c)take people to their desired floors, d)enable FIFO loading logic, e)remain on the floor if people are getting in or out. A solution that attempts to answer the above issues was devised and developed by establishing three different control modes. In each mode the elevator is controlled in a different way as follows: Mode 0 (QUIET MODE) - Elevator is parked (stationary) and is waiting for a call; Mode 1 (CALL MODE) - Elevator is responding to a call whilst empty; Mode 2 (OPERATING MODE) - Elevator is in motion and occupied.

In the baseline strategy the elevator moves in cases when a call is made either empty (Mode 1) or occupied (Mode 2). In all other cases, the elevator simply parks and waits at the last drop off floor (Mode 0). If the elevator is in Mode 2 and people are queued at the call point (in the correct direction of travel) then the elevator is allowed to pick up people, within its capacity (max 8 people). If the elevator is in Mode 1 and some people wait at a floor call point in direction of movement then priority exists for those people who have called the elevator first. Next, people who are waiting at other call points will be picked up in the direction of movement (max 8 people). People are dropped off in the sequence depending on who arrived first i.e. the person who made the first callwill be dropped off first (FIFO) then followed by the second person, etc.

Figure 1 (consider red boxes mainly) illustrates the Arena modelling screen displaying the control logic and animation of the baseline model as described above. The developed model could be divided into the following discrete stages: People entering the model; Making an elevator call; Elevator control logic; Elevator movement between floors

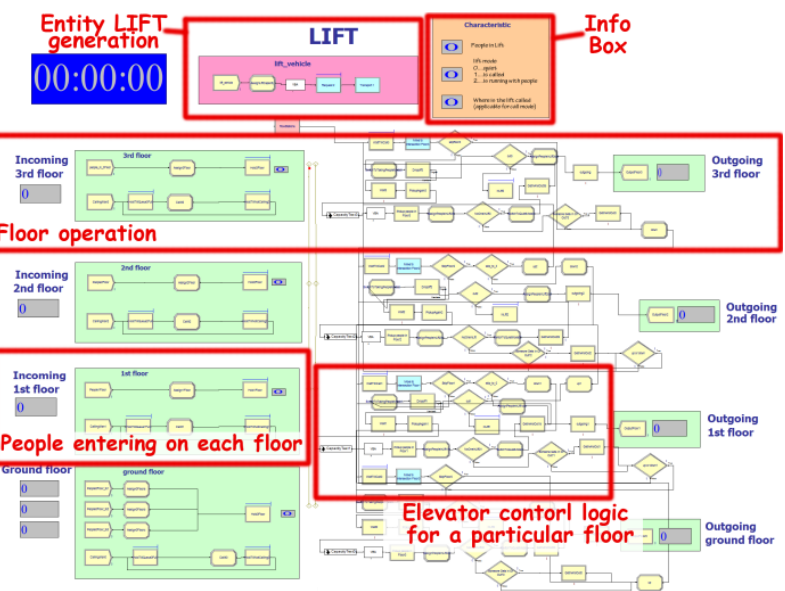

Fig. 1. Baseline Arena Model 


\section{SCENARIO TESTING}

More models for different dispatcher logic were made and tested. Reference Scenario 1 is the case where the elevator takes people in both directions and is able able to park if not in use. Eight different scenarios were considered including e.g. paternoster, duplex control, control to the terminal station etc. The criteria function consists mainly of the approximate waiting time of the people at particular floors. Reference Scenario 1 is found to be the best one for this criteria function.

\section{USER-DEFINED MODELS}

After validation of the strategies and many experiments, the idea of generalizing the simulation environment was formed. Adding a new floor or new elevator to the model used for the CASE STUDY is a difficult mechanical task where many hard to debug errors could occur. Therefore a common "sandbox" environment was developed for an easy-to-create dispatcher system for more floors and more elevators. The next task was to develop a user-friendly system where after entering the count of floors and count of elevators the model would be automatically generated. The first scenario was chosen as a reference model because it is fairly common. We also received the best results from experiments with this scenario.

There are more possible options at this moment. The method for the construction of the new template (plug-in) was chosen. ARENA enables user building blocks to be built up ('modules'). With the aid of the Arena Model Template package and Visual Basic for Applications, four new modules packed into a new plug-in (so called template) were developed: Init_Globals - Initialization of global variables; Elevator_Generator - Generator of a particular elevator (Nmodules for N-elevators in a model); Call_Floor - Logic control in front of elevator door (M-modules for M-floors in a model); Floor_Management - complex inside logic manages a particular elevator on a particular floor. This module links an elevator with a floor.

The functionality of the template panel was tested for more examples of buildings with more elevators. An example of a 3storey building with 3 elevators is shown in Fig. 2. There are many more parameters which can be user-defined in addition to the count of floors and elevators, e.g.: elevator capacities, elevator times (between floors, door operation time), ratio of incoming and outgoing people on each floor perhaps according to a random distribution, etc.
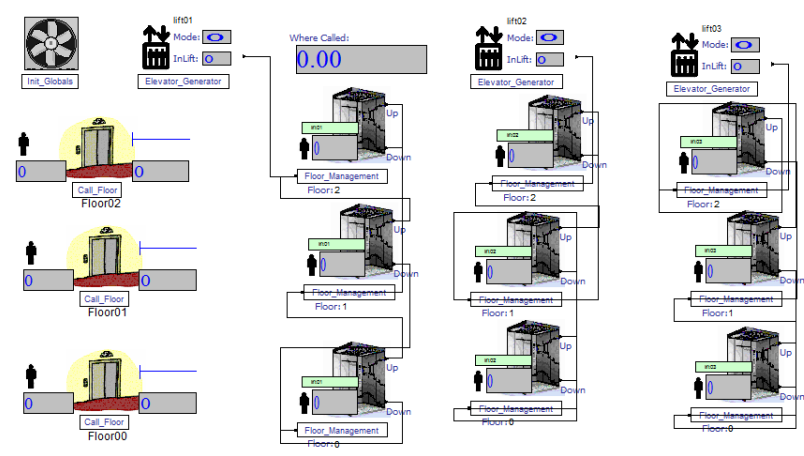

Fig. 2. Modules developed for a three-storey building with three elevators

\section{LMG - Lifts Model Generator}

The proposed architecture speeds up the construction of large scale elevator dispatcher system models exponentially but it also has a small disadvantage. The user still needs to manually drag and drop the modules and manually connect them. This manual work can also be automated. The LMG
(Lifts Model Generator) add-in package was also developed (see Fig. 3). The user can now construct an elevator dispatcher system for more kinds of buildings (e.g. skyscraper with more elevators) with just a few mouse clicks.

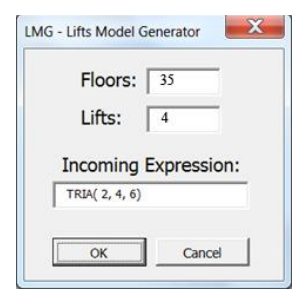

Fig. 3. LMG - Lifts Model Generator

\section{RESULTS AND FUTURE WORK}

Many experiments were also performed expecially for highrise buildings. For instance, for a 14-storey building with elevator cabin capacity of 8 people where people entering each floor most likely every 6 minutes (travel time between floors is 10 seconds, door operates for 20 seconds) the model shows $99.4 \%$ usage of elevator, where $63.4 \%$ is the work of the door and the average waiting time is more than 20 minutes. After addition of the second elevator the average waiting time is reduced to 2 minutes.

It is crucial to say that a unique and universal system for elevator dispatcher system control was made. The lift developers can virtually test the different usage of elevators, research the benefits of adding a new elevator to the building, simulate morning rush hours etc.

The system developed is limited by the size of the ARENA workbench (approx. 60 floors and 60 elevators). This limit can be easily modified but at the cost of model modification and lucidity for user. The artificial intelligence (e.g. intelligent seizing of elevators) and automatical optimization can be implemented.We are expecting to add a financial rating to the model. We are in the stage of acquiring data for this extension.

\section{ACKNOWLEDGEMENT}

This article was prepared with support of the Internal Science Foundation of the University of West Bohemia SGS2010-065.

\section{REFERENCES}

Berbeglia, G., Cordeau, JF., and Laporte, G. (2010) Dynamic pickup and delivery problems, European Journal of Operational Research, April 2010, Volume 202, Issue 1, ISSN 0377-2217, pp. 8-15

Lee, Y., Kim, T.K et al. Performance analysis of an elevator system during up-peak (2009). Mathematical and Computer Modelling, February 2009, Volume 49, Issues 3-4, ISSN 0895-7177, pp. 423-431

Sutton, R.S. and Barto, A.G. (1998) Reinforcement Learning: An Introduction: Elevator Dispatching. Massachusetts: The MIT Press, 1998, ISBN 0-262-19398-1

Simon, M.; Troblová, P. (2007) Effective Design Aspects of Production System, Annals of DAAAM for 2007 \& Proceedings of 18th international DAAAM symposium, Zadar, Croatia, 24-27 October 2007, ISBN 3-901509-58-5, Katalinic, B. (Ed.), pp 691-692, DAAM Int., Vienna

Yuan, X., Busoniu, L., and Babuska, R. (2008) Reinforcement Learning for Elevator Control. Proceedings of the $17^{\text {th }}$ International Federation of Automatic Control (IFAC) World Congress, Seoul, Korea, 6-11 July, 2008. ISBN 978-3902661-00-5, Chung, Myung Jin, (Ed.), pp 2212-2217, IFAC, Seoul 